ARTICLE

Received 21 Jan 2016 | Accepted 5 May 2016 | Published 14 Jun $2016 \quad$ DOl: 10.1057/palcomms.2016.27

\title{
Back to balance: labour therapeutics and the depoliticisation of workplace distress
}

James Davies ${ }^{1}$

ABSTRACT This article assesses the rise in diverse workplaces of what the author terms "labour therapeutics" - the application of therapeutic ideas and interventions to the understanding and management of employee distress. By way of an inductive narrative analysis of five institutional proponents of labour therapeutics, it concludes that the interventions and understandings labour therapeutics promote, by either individualizing employee distress or reducing it to the micro-arrangements of the workplace, inadvertently depoliticize the problem of work for growing numbers of individuals and organizations in the contemporary work setting. Further research is requested to explicate the confluence between neo-liberal working objectives and the new forms of labour therapeutic governance now in rapid ascent. This article is published as part of a collection entitled 'On balance: lifestyle, mental health and wellbeing'.

\footnotetext{
${ }^{1}$ University of Roehampton, London, UK Correspondence: (e-mail: jp.davies@roehampton.ac.uk)
} 
$\mathrm{n}$ recent years, the cost of mental health problems to developed economies has become a significant focus of governmental and global health institutions (WHO, 2013). In the United Kingdom, for example, government, advisors and clinicians among others have made the economic case for tackling the productive costs of poor mental health (for example, Department for Work \& Pensions [DWP], 2002; Social Exclusion Unit [SEU], 2004; Sainsbury Centre for Mental Health, 2007; Black, 2008; PricewaterhouseCoopers, 2008). This has led to investment in services explicitly aiming to reverse the "mental health burden" on employers and the state (MHF, 2010). The Layard report (2006) is a case in point-a combined UK government and clinical initiative leading to the Increased Access to Psychological Therapies programme (IAPT) whose "back to work" emphasis for sufferers of low mental health has sought to undo falling labour productivity and escalating mental health disability costs (Wesson and Gould, 2010). Despite wide government enthusiasm for the IAPT programme, which is dispensed through NHS clinics and, increasingly, job centres, it has been criticised for serving the neo-liberal discursive transformation of workforces into human resources, whose value becomes an "asset value" determined by productive output (James, 2008; Davies, 2011; Rizq, 2014). Through promoting psychological and moral dispositions conducive to labour efficiency, IAPT's "back to work" agenda has been seen as but one manifestation of how psychotherapeutics are being widely deployed in the interests of "capital" (House and Loewenthal, 2008; James, 2008; Roberts, 2015), either through individualizing, medicalising and psychologizing socially rooted despondency (Richman and Barry, 1985; Shields and Grant, 2010; De Vos, 2012), through medicalising unproductivity and so creating safe "exit strategies" for employers (Morrall, 2018), by deploying language that distorts communication for the purpose of mystifying workplace power dynamics (Habermas and Shapiro, 1972; Malhotra, 1987), or by pathologising low labour productivity to render it amendable to psychological screening, understanding and management (Wainwright and Calnan, 2002).

As there is yet to exist a shared interdisciplinary term to capture the application of diverse therapeutic ideas and interventions in the understanding and management of work related distress and low productivity, we shall here deploy the term "labour therapeutics" to denote such application. While labour therapeutics use diverse mechanisms of what Rose (1999) has termed social and occupational governmentality, the fora through which they have been deployed have been largely confined to clinical settings, affecting workplaces only exogenously. In recent years, however, a more direct penetration of labour therapeutics has influenced diverse workplaces, reshaping managerial modes of understanding and responding to worker distress in service of labour productivity.

This paper will therefore inspect this largely under-researched domain, by identifying the kind of labour therapeutics advocated and deployed by mental health charities and human relations consultancies, assessing the extent to which they are depoliticizing distress at work by framing and responding to it in terms attractive to employers. While these organizational interventions exercise a diversity of tropes, this paper will first pay special attention to the concept of work/life balance, which it will be argued has served, along with other tropes to be later inspected, to displace structural concerns about the meaning, value and nature of work in the neo-liberal era with a utilitarian and depoliticized emphasis on effective time-management, treatment seeking and improved mental hygiene. With respect to what is meant by the "neoliberal era" we refer to a form of capitalism, inauguration in the 1980s, in which market forces are freed to govern institutions hitherto owned, regulated or managed by the state. ${ }^{1}$

\section{Anthropologising the work/life balance}

Before commencing analysis of the narrative resources proper, some initial problematizing of the work/life balance concept is necessary. Since this concept was first coined in the 1980s, entering popular consciousness soon after (Burnett, 2011), it has been widely applied in psychological and occupational therapeutic literature to account for rising levels of work dissatisfaction (Greenhaus et al., 2003; Hill, 2004; Eby et al., 2005; Jones et al., 2006; Gröpel and Kuhl, 2009). At the moment Ronald Reagan's moral imperative that "hard work never killed anyone" was stealing individuals to what Richard Sennet called the demands of the "new economy" (Sennet, 2007), the concept of work/life balance seemed to offer a description of and a corrective to certain strains and stresses this new system ushered in: if work is encroaching too far into life, a new equilibrium and new balance must be sort (Gurvis and Patterson, 2004,2005). This concept's salience therefore grew in tandem with the rise of neo-liberal working arrangements, which were characterized by increased working hours, the growing necessity for duel-working households, the erosion of unionized working protections, the rise of short-termism and mobility in the employment market, and the rapid expansion of the service sector (Harvey, 2007; Kotz, 2015). While the use of the work/life balance concept in occupational and psychological literature has generally ignored such structural changes to the relations between capital and labour, its usage has also elided critical anthropological concerns. These include the concept's relativity rendering any general work-life proscriptions somewhat inoperative, and the concept's presupposing an almost natural opposition between work and life neither universally acknowledged nor accepted, especially in locales where work and life are conceptualized as having no clear and fast divisions. ${ }^{2}$

Notable examples of where culturally sanctioned work/life divisions enjoy little recognition or distinction can be found in diverse groupings where the characteristics most commonly associated with life - pleasurable activity, community, intimacyreach their highest expressions in the co-labouring realm; where people endeavour together in service of a calling or activity that ultimately grounds their purpose, meaning and social solidarity. While these expressions manifest in many artistic, intellectual and religious occupations operating in industrial settings, they also appear in diverse communities whose life-worlds have been revealed through sustained ethnographic enquiry, such as the Piaroa of Venezuela (Overing, 2003), the Nedembu of Zambia (Turner, 1967) and the Hadza of Tanzania (Marlowe, 2013) where in the latter, for example, we see enfolded in the work of hunting and gathering the ritual and meaning-making activities grounding community cohesion and purpose. For these and manifold other groups, the slicing of self into the living and labouring modes of existence does not reflect a partition rooted in some natural order, but rather certain social-cultural imperatives, which, in many contexts, can be traced to the demands of their political economies.

Where work/life separations are naturalized in industrialized settings is when symbolic boundaries demarcating the two domains are reified. Taking spatial boundaries as an example, work/life divisions may be weakened in contexts where "work" transpires in "living" spaces (for example, where labour transpires in the homestead) compared with where "work" and "life" are geographically separate (for example, where labour moves to local workshops or large urban factories). In these latter cases divisions are upheld through boundary enforcements of both symbolic and pragmatic salience. When considering what we may call the boundary of distance, for instance, in the United Kingdom the distance the average worker commutes back and forth each day is 17.4 miles, which computes to an average commuting time of $54 \mathrm{~min}$ per day, or $78 \mathrm{~min}$ if you work in London (National 
Centre for Social Research, 2007). In addition, the number of people commuting over 2 hours per day (approx. 3 million) has risen $72 \%$ since 2004 (TUC, 2015). While this temporal/spatial wedge serves to naturalize work/home demarcations, other boundaries such as the boundary of duration further compound the divide: since in the United Kingdom the average length of spent with a given employer is now approximately 6 years, with nearly $25 \%$ of the UK workforce having moved employers in the last year alone (Andersen, 2008; Macaulay, 2003), the durable relationships enabled at home, and once better enabled in the securer pre-neo-liberal job market, are less viable or even desirable in neo-liberal era of corporate mobility.

While many other boundaries obviously act to reinforce such divisions, such as the different modes of dress, aesthetics, behaviour, communication and styles of "emotional labour" pertaining to each zone, the central boundary from which this article gains its departure concerns how the zone of work, in contradistinction to the zone of life, is increasingly experienced as a domain of dissatisfaction and disengagement. Studies of worker satisfaction and engagement rates, despite the different protocols, measures and definitions employed, consistently locate the highest numbers of employees in the United Kingdom and the United States (approx. two thirds) in the "not engaged" or "dissatisfied" categories. ${ }^{3}$ In addition, rates of worker satisfaction and engagement have been in broad decline since the 1970s by between 8 and 19\%, depending on the study consulted, and notwithstanding some recent improvements. ${ }^{4}$ When evidence of these low and declining rates are set against studies into the relationship between work satisfaction and general well-being, which strongly associate higher job satisfaction with higher subjective well-being with correlations ranging from.19 to.49 (Faragher et al., 2005; Judge and Klinger, 2008), it is unsurprising that labour therapeutics are being recruited to understand and manage attending occupational and economic effects.

To understand precisely how such therapeutics are operating, a thematic narrative analysis was conducted on five organizations offering resources on workplace distress management. These comprised two large UK-based mental health charities (Depression Alliance; Mental Health Foundation); one Canadian based mental health organization (The Canadian Mental Health Association); one UK-based human resources organization (Advisory, Conciliation and Arbitration Service), which acts in concert with the European HR Leadership Forum; and one international consultancy (Mental Health First Aid). The selection criteria privileged organizations with a high public profile and developed workplace programmes offering advice to managers and/or employees about how to frame and respond to work-related distress. It also aimed for "representativeness", which was achieved through undertaking a wide literature review of related workplace programmes to ensure the organizations selected for analysis were as typical as possible. The ensuing analysis of the five organizations meeting these criteria, focused on their online campaigns and published workplace health reports exiting in the public domain from 2012. The initial reading and analysis of these resources was shaped by pre-existing questions concerning the management of employee distress; questions which were reduced to the following as a basis for further analysis and coding of the texts:

- What do these resources privilege (tacitly or overtly) as the most important causes of workplace distress?

- How do these resources frame the nature of such distress?

- What solutions do they advocate to address or resolve workplace distress?

Guided by these questions, the inductive analysis revealed two broad narrative themes by which these organizational resources frame and manage workplace distress. While both narratives use tropes that crossover at many points, sufficient differences were identified in how they responded to the above questions to warrant overall thematic separation into what will be classified as the "mental illness narrative" and the "work/stress narrative". Each will be addressed in turn.

\section{Mental illness narrative}

The two organizational texts emerging inductively as representing the mental illness narrative, were those produced by the Advisory, Conciliation and Arbitration Service (ACAS); and Depression Alliance. The first organization, ACAS, is a UK-based human relations organization "devoted to preventing and resolving employment disputes" (ACAS, 2015). It is largely funded by the UK Government's Department for Business Innovation and Skills, although it remains a non-departmental body overseen by an independent Council. Analysis focused on its published online report: Promoting Positive Mental Health at Work (ACAS, 2012) that teaches managers, among other things, how to identify and manage "mental illness" in their employees. Of the five organsational texts analysed across both narratives, the ACAS's report makes the only explicit link to the relevance of the wider "economic climate" on worker distress. As it states in the report's forward:

It's not hard to make the connection between the economic climate and the nation's mental wellbeing. When jobs are under threat, pay packets are being frozen, and workloads are increasing, employees' mental health is always likely to be affected. Over the last ten years, we have all noticed the increasing impact of mental ill health in the workplace. Stress, anxiety and depression, albeit not all work-related, have led to higher rates of absenteeism and lost productivity due to presenteeism. (ACAS, 2012: 2)

Acknowledging the economic roots of workplace anxiety and depression raises questions as to whether ACAS is conceptualizing workplace depression and anxiety in clinical or non-clinical terms; as "normal" or dysfunctional human responses to wider social pressures. The report tacitly addresses this query via its definition of anxiety and depression:

Mental ill health can range from feeling 'a bit down' to common disorders such as anxiety and depression and, in limited cases, to severe mental illnesses such as bipolar disorder or schizophrenia. (ACAS, 2012: 4)

The use of the term "disorder" suggests the terms depression and anxiety are being understood clinically, which is further supported by the claim that such disorders or "illnesses" have an agency of their own: "Some illnesses are persistent and may be classed as a disability ... while others come and go, giving the individual 'good days' and 'bad days'" (ACAS, 2012: 4). Framing disorders as ascribing good or bad days may subtly relocate the cause of mood fluctuations from variable environmental conditions to the dynamics of the disordered self. This consequent medicalization of responses to possible situational factors, over which individuals may also have limited control, is consistent with the report's emphasis on directing managers to identify and help employees who may be out of control. To assist managers in this task, the report moves counter to its opening statement by dissuading mangers from thinking about wider causes of workplace distress-stating these causes are very complex:

There are many possible causes of mental health conditions that can lead to a complex web of symptoms. Some of these 
causes may be related to workplace issues-a failure to get promotion, for example-but more often these will compound existing medical or personal problems. (ACAS, 2012: 9)

The view that workplace manifestations of depression and anxiety are more often clinical phenomena rooted in existing medical or personal problems, underpins the advice given to managers concerning how they should identify affected employees:

Illness is more easily understood if it is visible and mental illness may be less conspicuous than some forms of physical illness. An employee may also work very hard to disguise their symptoms, or they may develop other 'secondary symptoms' not directly related to the original problem-for example, the strain of coping with depression may cause someone to become dependent on alcohol or drugs. (ACAS, 2012: 5)

In view of the supposition that many employees may work very hard to disguise their symptoms managers are then advised how best to see through subterfuge. Firstly, they are told to "spot the signs", which initially means "taking a note of what you see as you walk around or in team meetings and then choosing the right moment to intervene" (ACAS, 2012: 10). What managers are asked to identify are what is referred to as "the common symptoms of mental ill health" (ACAS, 2012: 11). A list of what these symptoms might include is then provided to guide managers:

- an increase in unexplained absences or sick leave;

- poor performance;

- poor timekeeping;

- poor decision-making;

- lack of energy;

- uncommunicative or moody behaviour (ACAS, 2012: 11).

That none of these "symptoms" map onto official diagnostic criteria for depression or anxiety (American Psychiatric Association, 2013), is not acknowledged in the report. Nor is its queried that what is being classified as symptomatic of illness may simply capture non-disordered responses to a range of understandable human dilemmas, not least general work dissatisfaction and disengagement. After recasting common workplace problems as symptomatic phenomena, and after teaching managers how to "spot the signs", managers they are then asked to "Engage with the problem". This involves:

Developing a rapport with the employee will help you get a deeper understanding of their problem and identify: the best coping strategies for them to adopt [and] any specific triggers that set off symptoms. (ACAS, 2012: 11)

Identifying coping strategies is part of the wider organizational imperative of "honouring some legal requirements to make reasonable workplace adjustments to the working environment in certain circumstances", but also it involves referring people to employee assistance programmes for specialist mental health help such as counselling (ACAS, 2012: 10). In short, the narrative ACAS deploys, while paying initial lip-service to the relevance of wider social pressures, entails tutoring managers to frame workplace distress as best managed via clinical meanings and interventions.

The medicalising themes of the ACAS report, to be summarized presently, were also identified in the second organization, Depression Alliance, whose workplace campaign deployed similar tropes. Depression Alliance is a UK-based mental health charity that broadly characterizes itself as "supporting people with depression", largely through promoting peer support projects and anti-stigma campaigns. Analysis focused its online campaign launched in 2014 entitled: One in three people struggle to cope at work, a figure derived from its own survey of 1200 working people, conducted for Depression Awareness week. The webpage opens by summarizing the survey's core findings:

People struggle to cope at work because of depression, stress or burn out, with 83 per cent of those affected experiencing isolation or loneliness as a result (Depression Alliance, 2014).

The words "stress" and "burn out" suggest the struggle identified may at least be partly work-induced, but before this is further elaborated the reader is taken in a different direction by a quote from the Chief Executive of Depression Alliance, Emer O'Neill, who emphasizes the word "depression" in his call for greater managerial support:

Depression is the biggest mental health challenge among working-age people and often leads to considerable loneliness and isolation at work. However, many companies aren't properly equipped to manage employees who suffer from depression so providing support to these individuals in the workplace is essential. (Depression Alliance, 2014)

This statement introduces ambiguity as to whether the survey's findings refer to the prevalence of a work-induced problem or a clinically rooted disorder called "depression" for which employers need to be better prepared and equipped. This ambiguity remains until the webpage refers the reader for further information to the Target Depression in the Workplace (HR Leadership Forum, 2014) report, produced by the European HR Leadership Forum. This report asserts a different emphasis, preferring the phrase "depression in the work place" to Depression Alliance's phrase "struggling to cope at work". The first line of the report then informs the reader not only what depression is but how it affects individuals at work:

Depression is a 'brain-based' disorder and is the principal source of workplace disability, attacking the individual's ability to concentrate and work productively ... one in five workers in Europe had been diagnosed with the condition at some stage. (HR Leadership Forum, 2014: 17)

The unsubstantiated declaration that depression is a "brainbased disorder", nevertheless acts to move "struggles at work" into the realm of medical heuristics. This idea is further strengthened by the iatric rhetoric the report continues to deploy: "Treatment of depression is more successful when the condition is diagnosed and treated early on" (Ibid.: 14). Such early treatment is important because:

[depression] causes considerable reduction in productivity due to the impairment from cognitive symptoms, which has significant cost implications from both an economic and individual business perspective' .... (Ibid.: 18) [After all] “depression cost[s] UK employers $£ 26$ billion every year (Ibid.: 6).

Once the nature and costs of depression have been established, the report provides a case study of workplace "best practice" in depression management. This is derived from the BT Group's Workplace Initiative, launched in 2002, which makes use of a "three-tier framework" for affected individuals comprising "prevention, intervention and rehabilitation". To focus on the 
practical support offered at each tier, the first tier (primary prevention) advocates the "adoption of flexible working ... to help balance work and home commitments" (Ibid.: 13). Prevention is thus located in attaining flexible work/life arrangements, rather than questioning the nature of the work and its attending affects with which one must better balance one's life. The second tier (secondary intervention) advocates "availability of confidential employee assistance programmes" (Ibid.: 13), which are largely outsourced to private providers that help employees manage those "personal problems" impacting adversely on work performance, health and well-being. Through personalizing problems these programmes do not only assist employees, but also employers, by advocating productivityenhancing "back to work" therapeutics. Finally, the third tier (tertiary rehabilitation) advocates "provision of psychological support (CBT) services for mentally ill staff" (Ibid.: 13). While this rehabilitative phase assumes "mentally ill" staff can be effectively identified, the support preferred is cognitive behavioural therapy (CBT); an approach that aims to change unhelpful patterns of thought and behaviour rather than the situational factors to which individuals are subject.

The Depression Alliance campaign, via the target depression report, can be interpreted as subtly recasting the "struggle at work" with which most people can identify as an experience for which psychological/medical understanding and intervention may be necessary, underscoring the preference for correcting individuals through therapeutics over addressing wider macropressures on labour. In this respect, both ACAS and Depression Alliance have narrative recourse to locating employee despondency within factors for which the individual is largely responsible, whether in low resilience or in a latent or existing mental health condition that work can trigger or exacerbate. In so doing, both are liable to confuse manifestations of non-medical employee dissatisfaction and disengagement with the so-called clinical symptoms of mental ill health, thereby eliding situational drivers as a matter for organizational scrutiny or concern.

\section{Work-stress narrative}

If the mental health narrative broadly tends to medicalise causes and solutions for employee distress, what is termed the "work/ stress narrative" is more sympathetic to, firstly, the effects of the immediate or micro-working conditions upon the person, and secondly, to the person's relationship with work itself-namely, their work/life balance. The first organization from which this narrative was inferred is Mental Health First Aid England (MHFAE), which is the national arm of an international organization established in 2006 and recognized in 36 countries. MHFAE runs courses training what they call "mental health first aiders"-these are the "go-to colleagues" in the office who can help a person in emotional distress. To date, MHFAE has trained over 12,000 instructors in England, who have delivered courses to over 94,000 potential "first aiders". MHFAE's aim is to train one in ten employees in England. First aiders are taught to "identify, understand and help a person who may be developing a mental health issue" (MHFAE, 2015). They are asked to provide a listening ear, walks in the park, desk swaps so sufferers can sit somewhere quieter and assistance with "to do" lists, among other things. MHFAE (2015) articulates the training of first aiders as part of a wider social objective "to increase the mental health literacy of the whole population". It claims that a company's use of MHRA's services "will contribute to a good Corporate Social Responsibility programme", while also increasing "productivity and employee loyalty" (MHFAE, 2015).

While medical tropes permeate this narrative too, they do so in comparatively mitigated form, for although the word "symptom" is frequently deployed throughout MHFA's resources to capture expressions of distress at work, the more neutral phrase "mental ill health" is preferred over "mental illness". This corresponds with the notion that while stress is seen as potentially causing disorder, it is not a disorder in itself. This protects against the medicalization of an experience (stress) that at lower levels is associated with high productivity, while at the same time legitimating non-medical or therapeutic ways of managing distress. This latter emphasis departs from that expressed in the mental illness narrative by privileging the micro-management of the individual's working environment as a first line response, only recommending therapeutic interventions where microinterventions fail. This general orientation is captured in the MHFAE's (2013) Line Manger's Resource, a flagship document advising managers how to identify and mange workplace distress with the aim of increasing well-being and productivity within the existing culture of the organization. As it states:

As a manager you should be aware of the wider organisation's impact on employees. It might be the case that certain tasks, work environments, times of the day or particular teams are more likely to be associated with employees experiencing difficulties (MHFAE, 2013: 14).

Managers are therefore asked to adopt the following practices to facilitate work-place well-being:

- developing a work culture where everyone is treated with respect and dignity;

- developing a culture of open and honest communication, where staff know that it is OK to talk about mental health and that it is safe to disclose their experiences;

- giving employees control over their work;

- ensure that the employee has the right level of skills for the job;

- making sure that staff have a manageable workload;

- operating flexible working hours so that employees can balance the demands of home life with work;

- check the work environment and eliminate stressors such as flickering lights (Ibid.: 10).

While developing a healthy working culture is prioritized as corrective to workplace distress, managers are cautioned that poor mental health can still frustrate even the most equitable working environment:

If someone is having frequent short bursts of sickness absence with a variety of reasons such as stress, migraines, and back pain or there is no reason given, there may be an underlying mental ill health issue that should be discussed (Ibid.: 15).

Where workplace micro-interventions fail to promote wellbeing, in other words, the mental ill health trope is recruited to explain the failure away. As previously identified in the mental illness narrative (for example, ACAS), managers are also told to be aware of the signs. In this case they are asked to note changes in an employee's usual behaviour such as an increase in "poor performance, tiredness or increased sickness absence ... an increased use of alcohol, drugs or smoking ... [or] loss of humour and changes in emotions or mood" (Ibid.: 14). Other telling signs include: "A normally punctual employee might start turning up late or experience problems with colleagues. Conversely, an employee may begin coming in much earlier and working later" (2013: 14). If such behaviour continues despite alterations to the micro-working environment, managers are encouraged as a "second line response" to again refer employees to "employment 
assistance programmes" (Ibid:: 13). Here individuals can be referred for company counseling or NHS psychotherapy, provided through the "back to work" IAPT schemes. Where such company programmes do not exist, managers are asked to encourage distressed employees to consult their G.P (Ibid.: 21).

While First Aid England is representative of the micromanagement tradition's emphasis on rooting occupational despondency in unhelpful micro-working conditions and, in unresponsive cases, in a person's mental ill health, the next organization, The Canadian Mental Health Association (CMHA), provides an example of organization within the work/stress narrative that highlights a work/life imbalance as a core determinant employee despondency. CMHA is a nation-wide, voluntary organization "supporting the resilience and recovery of people experiencing mental illness". Their online campaign Your Mental Health (CMHA, 2015) includes a resource entitled "Work Life Balance", whose primary focus is to encourage Canadian workers to strike a healthier work/life balance. As it states in the introductory paragraph:

More than ever before, Canadians play many different roles in their lives. They are workers, parents, spouses, friends, caregivers of elderly relatives and volunteers in their communities. They must also make room in their lives for taking care of their own physical and mental well-being. Not surprisingly, achieving balance among all these competing priorities can be difficult (CMHA, 2015).

There then follows a short 30-second animated film depicting a father who is unhappy at work, and narrated by a little girl (his daughter) who speaks over a procession of images she has supposedly drawn (CMHA, 2011). The first images depict a stickfigure father with a smiling face hugging his daughter and playing ball with her in the garden - a sun shines brightly in the background and a big pink flower is in bloom. Over the image the little girl narrates: "My daddy is the bestest daddy in the world. We play, laugh and have lots of fun, before he goes to work". Once the word "work" is introduced, the images alter in form. The first depicts a sad father leaving for work in his car, with dark clouds brooding above; there follows a close-up image of a red tear rolling down his cheek. Finally we see a little stick-girl with a melancholy face holding a sad-faced teddy. The girl's narration continues: "When my daddy comes home he looks very tired and sad, I wish my bear could make my dad feel happy again. Or maybe someone else could help him, maybe someone like you". The final image portrays a sad-faced father, head in hands, sitting at a desk with a clock behind depicting 5 o'clock.

This film clearly conveys that work is an unhappy burden for this father, while stressing how his suffering affects his family. The film avoids offering reasons for the father's predicament, which enables the viewer to project their suppositions onto the scene. This lack of specificity also serves to capture a diversity of experience (for example, general dissatisfaction, meaninglessness, boredom, insecurity), as well as a diversity of potential causes (for example, meaningless work, poor working conditions, low pay or status). The film's power is therefore located in its capacity to speak to nearly anyone experiencing discontent at work for whatever reason, while increasing the gravity of workplace distress by depicting its consequent domestic effects.

While the film avoids stating the causes for workplace discontent, from the solutions offered in the ensuing resource they can nevertheless be inferred. The first arrives in the form of an online survey comprising 30 questions, called the Mental Health Meter. This is devised "to help you reflect on your unique strengths and identify areas where your level of mental fitness could be improved to help you cope with all of life's up and downs". The questions assess general levels of individual resilience, self-actualisation, ability to enjoy life and flexibility, thus subtly rooting work distress in a relative lack of these individual qualities. The Mental Health Meter is then supplemented by a Work/Life Balance Quiz, which participants can undertake to ascertain whether they are dedicating sufficient time to friends, family, hobbies and outside interests. One again, the stress on striking a more equitable work/life balance serves to predicate distress in an ailing capacity for counterpoise than in the nature of the work with which temporal harmony is sought (CMHA, 2015).

This emphasis on striking the right balance was also made by the final organization subject to analysis, The Mental Health Foundation (MHF). MHF is one of the UK's largest mental health charities, which works to "end the inequalities that face people experiencing mental health problems, living with learning disabilities or reduced mental capacity" (MHF, 2015). Its online resource entitled Work Life Balance (MHF, 2015) recognizes that micro-working conditions (for example, too low or too high a workload, impossible deadlines, unclear priorities and targets, low task variety, poor management, low interpersonal support) can contribute to high stress, anxiety and depression. However, the resource implies such micro-working conditions are secondary to what it highlights as the essential problem at work:

The pressure of an increasingly demanding work culture in the $\mathrm{UK}$ is perhaps the biggest and most pressing challenge to the mental health of the general population. The cumulative effect of increased working hours is having an important effect on the lifestyle of a huge number of people, which is likely to prove damaging to their mental well-being .... A key way to protect your mental health against the potential detrimental effects of work related stress is to ensure you have a healthy work-life balance (MHF, 2015).

To address this challenge they offer the following solutions to help sufferers strike a better work/life balance:

- Take personal responsibility for your work-life balance. This includes speaking up when work expectations and demands are too much.

- Try to "work smart, not long".

- Take proper breaks at work.

- Try to ensure that a line is drawn between work and leisure.

- Take seriously the link between work-related stress and mental ill health.

- Recognize the importance of protective factors, including exercise, leisure activities and friendships.

- Watch out for the cumulative effect of working long hours by keeping track of your working hours over a period of weeks or months rather than days (MHF, 2015).

In their accompanying booklet How to Manage and Reduce Stress (MHF, 2013), which is primarily directed towards employees, further solutions to work-stress are advanced under the heading "How to Help Yourself". Apart from re-emphasising the points listed above, plus highlighting the importance of selfmonitoring and "reviewing your lifestyle", the booklet asks employees as a key component of self-care, to "identify the causes" of their distress. However, it does so with an important caveat:

Sort the possible reasons for your stress into those with a practical solution, those that will get better anyway given time, and those you can't do anything about. Try to let go of those in the second and third groups-there is no point in worrying 
about things you can't change or things that will sort themselves out (Ibid.: 18).

This last statement indicates there are domains of life over which we have little control. Presumably these domains include those about which MFH remains silent, such as wider political and social structural pressures that impinge upon working life. The Mental Health Foundation's advice "that there is no point in worrying about things you can't change" is the only explicit reference in the surveyed literature to a directive tacitly permeating all resources assessed: that wider socio-political drivers of workplace distress are beyond the scope of consideration in terms of both management and understanding.

The work/stress narrative as inferred from MHFAE, CMHA and the MHF, is sympathetic to the effects of micro-working conditions upon the person, and to the person's relationship with work itself (that is, their work/life balance). Furthermore, this narrative broadly characterizes employee stress as a non-medical experience, which may be even desirable at low levels insofar as it motivates employees and boosts their productivity. Where stress is cast as problematic is in its severer or more protracted manifestations, which it characterizes as potentially disposing individuals to mental health conditions such as depression and anxiety. Here the emphasis is not on latent mental health conditions that circumstances simply trigger, as much as on circumstances that produce stress to the extent they generate a hitherto suffered mental disorder.

\section{Discussion}

From the organizational documents assessed above, a broad series of themes begin to emerge. While the mental illness and work/ stress narratives each offer different emphases with respect to the levels of medical language deployed and the species of intervention primarily preferred (therapeutic or workplace interventions), there is nevertheless sufficient cross-over in many essential characteristics to warrant capturing their basic position under the following two propositions:

- High and escalating rates of work dissatisfaction and disengagement are ignored as potentially causative of employee despondency. Such experiences are liable to being either confused with or reframed as mental ill health, stress or burnout rooted in either psycho/biological factors and/or the micro-arrangements of the workplace.

- Both narratives offer solutions that are therefore highly circumscribed: either favouring psycho/biological explanations that invite therapeutic interventions (mental health narrative), micro-environmental explanations that invite microalternations to the work setting, or a rebalancing of one's relationship to that setting (work/stress narrative).

The proponents of such narratives may well argue they are performing a vital public service by emphasizing the links between work and emotional health; by suggesting that working too hard for too long can be harmful; by insisting that the workplace must conduce to greater well being; by urging managers to be sympathetic and tolerant of employees in emotional need, and by advocating the offering of support where required. When and where such interventions mitigate distress their arguments gain currency. Where criticism of both narratives is warranted, however, is in noting their essential servility to existing macro-neo-liberal working culture. They operate within a tight epistemic frame that assumes the inevitability of current corporate and managerial arrangements, and which bypasses critical reflection on the form of political economy by which modern work is structured. In locating the causes of despondency in persons and their micro-working surroundings, both of which they endeavour to monitor and correct, they have assumed the exhaustion of more social democratic alternatives to the market, helped reify culturally situated divisions between work and life, overlooked widespread alienation in the world of work and production, further eroded the viability or even desirability of collective solutions at work and subtly accepted that increased labour productivity, rather than the nurturance of wider human potential, is primary goal of their interventions. By either individualizing employee despondency or reducing it to the micro-arrangements of the workplace, they help to inadvertently depoliticize the problem of work for the growing numbers of individuals and organizations, thus deflecting critique from the socio/economic strictures and structures to which individuals and organizations must adapt to secure their livelihood. ${ }^{5}$

While it remains moot whether different proponents of the "mental health" and "work/stress narratives" acknowledge that the experience of paid employment for increasing numbers is one of not only dissatisfaction and disengagement, but of boredom, unfulfilled potential, frustration and uncertainty (Wainwright and Calnan, 2002), to the extent they medicalise what are nonmedical human reactions via "labour therapeutics" they may advance a political quietism, obscuring the wider socio-political drivers of workplace distress. These resources, after all, target struggling employees or those expected to manage them; those often lacking the time, the occupational safeguards and in some cases the critical resources to scrutinize where labour therapeutics operate ideologically. Where further analyses of labour therapeutics therefore become essential, is through examining how hegemonic articulations of labour distress may be contested by antagonistic employee discourses and how such dissonant articulations are institutionally configured and managed; whether different demographics of gender, age, religion and ethnicity display dissimilar levels of therapeutic engagement and/or institutional targeting; how do (and what are) the mechanisms by which labour therapeutics penetrate diverse labour markets despite absent independent outcome studies as to their occupational effects; what are the interests served and the benefits accrued by the architects of labour therapeutics; and finally, beyond the mechanisms here identified, what other therapeutic devices operate in ways primarily serving the neo-liberal preference for capital. In sum, as labour therapeutics often entail coercive use of psycho/medical narratives there is good reason to call for more independent research to trace and clarify the confluence between neo-liberal working objectives and the new forms of labour therapeutic governance now in rapid ascent.

\section{Notes}

1 While definitions of neo-liberalism are varied and diverse (Thorsen and Lie, 2006), there is sufficient consensus to warrant a working definition for the purpose of this chapter. This definition follows that advanced by David Kotz, who defines neoliberalism not only as a set of ideas, or as an ideology, but as a political commitment to reduce the role of non-market institutions in the economy-such as the state, trade unions and corporate bureaucracies (Kotz, 2015: 8-9).

2 The collapsing of this division has its earliest roots in Karl Marx's writings on alienation: "What then constitutes the alienation of labour? .... the fact that labour is external to worker, i.e. it does not belong to his essential being; that in his work, therefore, he does not feel content but unhappy, does not develop freely his physical and mental energy but mortifies his body and ruins his mind. The worker therefore only feels himself outside his work, and in his work feels outside himself. He is at home when he is not working, and when he is working he is not at home. His labour is therefore not the satisfaction of a need; it is merely a means to satisfy needs external to it. Its alien character emerges clearly in the fact that as soon as no physical or other compulsion exists, labour is shunned like the plague" (Marx, quoted in Bocock, 1993: 46). 
3 For instance, a CIPD report conducted in 2013 showed that, on average, the percentage of those reporting job satisfaction in the UK was $40 \%$, with the lowest figures found in the public sector (25\%) and in large business (30\%) (CIPD, 2013). These results are broadly consistent with many earlier studies such as a 2007 study which assessed 1200 Britons, and revealed two thirds said they were "unfulfilled", "miserable" or "drifting" in their jobs, with over $52 \%$ stating they would happily earn less money in a role that made them feel better about themselves (James, 2008:151). Similar trends are found in the US employment market. For instance the Conference Board report in 2013 based on a survey of 5,000 U.S. households, found that US job satisfaction had reached an all-time low by 2010 , with only $42.6 \%$ claiming to experience work satisfaction (Ray, 2013). In recent years measures of job satisfaction have been supplemented with measures of "job engagement"-that is, the level of commitment, emotional and cognitive interest and enjoyment one finds in their work. Here Truss et al. (2006) cross-sectional survey of UK workers from various industries found only $35 \%$ of employees engaged overall, while an earlier UK Gallup survey found that only $17 \%$ were "engaged employees" (that is, loyal, committed, productive and task-effective). The majority, $63 \%$, were "non-engaged employees" (that is, would do what was asked of them, routinely, tempted to by job vacancies elsewhere, cynical about loyalty). The remaining 20 per cent were actively disengaged (that is, physically present, but psychologically absent) (Buckingham, 2001).

4 While changes in rates of satisfaction and engagement fluctuate from year from year, historically job satisfaction and engagement has been trending downwards since the 1970 s. In the United States those who were very satisfied with their jobs fell by $8 \%$ between the mid-1970s and the mid-1990s (Blanchflower and Oswald, 1999), with a similar trend in the United Kingdom (Kular et al., 2008). Other studies have put the decline in satisfaction higher-again, the the Conference Board's survey showed job satisfaction has decreased from $61.1 \%$ in the mid-1980s (1987) to $42.6 \%$ by 2010 -thus dropping a full $19 \%$ over 25 years (Ray, 2013).

5 In this there is agreement with the sociologists Wainwright and Calnan (2002) who state that: “... heavy workload, intensive working, coercive management and other problems at work are no longer seen as collective issues to be fought over though industrial action or political activity, but as individualized threats to the mental and physical health of the worker, to which therapeutic intervention is the proper response" (161).

\section{References}

ACAS. (2012) Promoting Positive Mental Health at Work, http://www.acas.org.uk/ media/pdf/j/i/Promoting_positive_mental_health_at_work_JAN_2012.pdf, accessed January 2014

ACAS. (2015) Home Page, http://www.acas.org.uk/index.aspx?articleid=1461, accessed January 2016.

Andersen T (2008) Job Mobility in the European Union: Optimising its Social and Economic Benefits. European Commission. Danish Technological Institute, final report, Copenhagen, Denmark.

American Psychiatric Association. (2013) Diagnostic and Statistical Manual of Mental Disorders, 5th edn., APA: Washington DC.

Black C (2008) Working for a Healthier Tomorrow, https://www.gov.uk/ government/uploads/system/uploads/attachment_data/file/209782/hwwb-work ing-for-a-healthier-tomorrow.pdf, accessed January 2015.

Blanchflower DG and Oswald AJ (1999) Well-Being, Insecurity and the Decline of American Job Satisfaction, http://www.dartmouth.edu/ blnchflr/papers/Job Sat.pdf, accessed June 2014.

Bocock R (1993) Consumption (Key Ideas). Routledge: London.

Buckingham M (2001) What a waste. People Management, http://www.cipd.co. uk/pm/peoplemanagement/b/weblog/archive/2013/01/29/1163a-2001-10.aspx, accessed June 2015.

Burnett K (2011) Practical Contact Center Collaboration. Rosedog Press: Pittsburgh, Pennsylvania.

Canadian Mental Health Association (CMHA). (2011) Workplace Mental Health PSA, http://cmhaff.ca/videos, accessed January 2014.

Canadian Mental Health Association (CMHA). (2015) Your Mental Health, https://www.cmha.ca/mental-health/your-mental-health/, accessed May 2015.

Chartered Institute of Personnel and Development. (2013) Employee Outlook, http://www.cipd.co.uk/binaries/employee-outlook_2013-autumn.pdf, accessed October 2014.

Davies W (2011) The political economy of unhappiness. New Left Review; 71, 65-80.

De Vos J (2012) Psychologisation in Times of Globalisation (Concepts for Critical Psychology). Routledge: London.

Department for Work \& Pensions. (2002) Pathways to Work: Helping People into Employment, http://www.scie-socialcareonline.org.uk/pathways-to-work-help ing-people-into-employment/r/a11G00000017uqaIAA, accessed 24 July 2015.

Depression Alliance. (2014) One in Three People Struggle to Cope at Work, http:// www.depressionalliance.org/news-blogs/news/one-three-people-struggle-copework, accessed June 2014.

Eby LT, Casper W, Lockwood A, Bordeaux C and Brinley A (2005) Work and family research in IO/OB: Content analysis and review of the literature (1980-2002). Journal of Vocational Behavior; 66 (1): 124-197.
Faragher EB, Case M and Cooper CL (2005) The relationship between job satisfaction and health: A meta-analysis. Occupational and Environmental Medicine; 62 (2): 105-112.

Greenhaus JH, Collins KM and Shaw JD (2003) The relation between workFamily balance and quality of life. Journal of Vocational Behaviour; 63 (3): 510-531.

Gröpel P and Kuhl J (2009) Work-Life balance and subjective well-being: The mediating role of need fulfillment. British Journal of Psychology; 100 (2): $365-375$.

Gurvis J and Patterson G (2004) Finding Your Balance. Center for Creative Leadership: Greensboro, NC.

Gurvis J and Patterson G (2005) Balancing act: Finding equilibrium between work and life. Leadership in Action; 24 (6): 4-9.

Habermas J and Shapiro J (1972) Knowledge and Human Interests. Beacon Press: London.

Harvey D (2007) A Brief History of Neoliberalism. Oxford University Press: Oxford. Hill JE (2004) Finding an extra day a week: The positive influence of perceived job flexibility on work and family life balance. Family Relations; 50 (1): 49-58.

House R and Loewenthal D (2008) Against and for CBT: Towards a Constructive Dialogue? PCCS Books: London.

HR Leadership Forum. (2014) Depression in the Workplace in Europe: A Report Featuring New Insights from Business Leaders, http://targetdepression.com/wpcontent/uploads/2014/04/TARGET_Report_Final.pdf, accessed June 2104.

James O (2008) The Selfish Capitalist: The Origins of Affluenza. Vermillion: London.

Jones F, Burke RJ and Westman M (2006) Work-Life Balance: A Psychological Perspective. Psychology Press: London.

Judge TA, Klinger R (2008) Job satisfaction: Subjective well-being at work. In: Eid M and Larsen RJ (eds) The Science of Subjective Well-Being. Guildford Press: London.

Kotz DM (2015) The Rise and Fall of Neoliberalism. Harvard University Press: Boston, MA.

Kular S, Gatenby M, Rees C, Soane E and Truss K (2008) Employee engagement: A literature review. Working Paper Series No 19. Kingston Business School, http:// eprints.kingston.ac.uk/4192/1/19wempen.pdf, accessed January 2014.

Layard L (2006) The Depression Report: a new deal for depression and anxiety disorders. The Centre for Economic Performance's Mental Health Policy Group, LSE.

Macaulay C (2003) Job Mobility and Job Tenure in the UK. London: Office for National Statistics, http://www.statistics.gov.uk/articles/labour-market-trends/ jobmobility-nov03.pdf, accessed June 2014.

Malhotra VA (1987) Habermas' sociological theory as a basis for clinical practice with small groups. Clinical Sociology Review; 5 (1): 181-192.

Marlowe F (2013) The Hadza: Hunter-Gatherers of Tanzania (Origins of Human Behavior and Culture). University of California Press: Berkeley, CA.

Mental Health First Aid England (MHFAE). (2013) Line Managers' Resource, http://mhfaengland.org/files/5613/9101/5215/MHFA_Line_Managers_Resource .pdf, accessed June 2015.

Mental Health First Aid England (MHFAE). (2015) Mental Health First aid England, http://mhfaengland.org/, accessed June 2015.

Mental Health Foundation (MHF). (2010) Economic Burden of Mental Illness Cannot be Tacked Without Research Investment, http://www.mentalhealth.org. $\mathrm{uk} /$ content/assets/PDF/campaigns/MHF-Business-case-for-MH-researchNov2010.pdf, accessed December 2013.

Mental Health Foundation (MHF). (2013) How to Manage and Reduce Stress, http://www.mentalhealth.org.uk/content/assets/PDF/publications/how_to_ stress.pdf?view $=$ Standard, accessed October 2014.

Mental Health Foundation (MHF). (2015) Work-Life Balance, http://www. mentalhealth.org.uk/help-information/mental-health-a-z/w/work-life-balance/, accessed January 2015.

Morrall P (2018) The Trouble with Therapy: Sociology and Psychotherapy. Open University Press: London.

National Centre for Social Research. (2007) Travel to Work-Personal Travel Factsheet, http://webarchive.nationalarchives.gov.uk/+/http:/www.dft.gov.uk/ $\mathrm{pgr} /$ statistics/datatablespublications/personal/factsheets/traveltowork.pdf, accessed August 2014

Overing J (2003) In praise of the everyday: Trust and the art of social living in an Amazonian community. Ethnos; 68 (3): 293-316.

PricewaterhouseCoopers LLP. (2008) Building the Case for Wellness, https://www. gov.uk/government/uploads/system/uploads/attachment_data/file/209547/ hwwb-dwp-wellness-report-public.pdf, accessed June 2015.

Ray RL (2013) Job Satisfaction: 2013 Edition (Conference Board), https:// hcexchange.conferenceboard.org/publications/publicationdetail.cfm?publicatio nid $=2522$, accessed December 2014.

Richman A and Barry A (1985) More and more is less and less the myth of massive psychiatric need. The British Journal of Psychiatry; 146 (2): 164-168.

Rizq R (2014) Perversion, neoliberalism and therapy: The audit culture in mental health services. Psychoanalysis, Culture \& Society; 19 (2): 209-218.

Roberts R (2015) Psychology and Capitalism: The Manipulation of Mind. Zero Books: London. 
Rose N (1999) Governing the Soul: Shaping of the Private Self. Free Association Press: London.

Sainsbury Centre for Mental Health. (2007) Mental Health at Work: Developing the Business Case, Policy Paper 8, http://www.impact.ie/wp-content/uploads/ 2015/07/Mental-Health-at-Work.pdf, accessed June 2015.

Sennet R (2007) The Culture of the New Capitalism. Yale University Press: New Haven, CT.

Shields J and Grant D (2010) Psychologising the subject: HRM, commodification, and the objectification of labour. The Economic and Labour Relations Review; 20 (2): 61-76.

Social Exclusion Unit. (2004) Mental Health and Social Exclusion, http://www.nfao.org/ Useful_Websites/MH_Social_Exclusion_report_summary.pdf, accessed May 2015.

Thorsen DE and Lie A (2006) What is Neoliberalism? Department of Political Science, University of Oslo: Oslo, Norway, Manuscript.

Truss C, Soane E and Edwards C (2006) Working Life: Employee Attitudes and Engagement. CIPD: London.

TUC (2015) Number of Commuters Spending more than two Hours Travelling to and from Work up by $72 \%$ in Last Decade, https://www.tuc.org.uk/workplaceissues/work-life-balance/number-commuters-spending-more-two-hours-travel ling-and-work-72, accessed November 2015.

Turner V (1967) The Forest of Symbols: Aspects of Ndembu Ritual. Cornell University Press: New York.

Wainwright D and Calnan M (2002) Work Stress: The Making of a Modern Epidemic. Open University Press: London.

Wesson G and Gould M (2010) Can a "return-to-work" agenda fit within the theory and practice of CBT for depression and anxiety disorders? The Cognitive Behaviour Therapist; 3 (1): 27-42.
World Health Organization. (2013) Mental Health Action Plan: 2013-2020. WHO Press: Switzerland.

\section{Data availability}

Data sharing not applicable to this article as no data sets were generated or analysed during the current study.

\section{Additional information}

Competing interests: The authors declare no competing financial interests.

Reprints and permission information is available at http://www.palgrave-journals.com/ pal/authors/rights_and_permissions.html

How to cite this article: Davies J (2016) Back to balance: labour therapeutics and the depoliticisation of workplace distress. Palgrave Communications. 2:16027 doi: 10.1057/ palcomms.2016.27

\section{(c) (i)}

This work is licensed under a Creative Commons Attribution 4.0 International License. The images or other third party material in this article are included in the article's Creative Commons license, unless indicated otherwise in the credit line; if the material is not included under the Creative Commons license, users will need to obtain permission from the license holder to reproduce the material. To view a copy of this license, visit http://creativecommons.org/licenses/by/4.0/ 